\title{
Basal Stem Rot of Broccoli Caused by Rhizoctonia solani AG-2-1 and AG-4 in Korea
}

\author{
Wan-Gyu Kim ${ }^{1 *}$, Gyo-Bin Lee ${ }^{2}$, Hong-Sik Shim ${ }^{1}$ and Weon-Dae Cho ${ }^{3}$ \\ ${ }^{1}$ Research Committeeman, Global Agro-Consulting Corporation \\ ${ }^{2}$ Researcher, Global Agro-Consulting Corporation \\ ${ }^{3}$ Managing Director, Global Agro-Consulting Corporation \\ *Corresponding author: Wan-Gyu Kim, Global Agro-Consulting Corporation, Hwaseong 18330, Korea
}

\section{ARTICLE INFO}

Received: 幽 December 14, 2020

Published: 幽 December 21, 2020

Citation: Wan-Gyu Kim, Gyo-Bin Lee, HongSik Shim and Weon-Dae Cho. Basal Stem Rot of Broccoli Caused by Rhizoctonia solani AG2-1 and AG-4 in Korea. Biomed J Sci \& Tech Res 32(4)-2020. BJSTR. MS.ID.005294.

\section{ABSTRACT}

Basal stem rot symptoms were frequently observed on broccoli plants grown in farmers' fields located in Gimje and Jeju, Korea during disease surveys carried out in November and December 2019. Incidence of the diseased plants was 1-10\% in the fields investigated. Five isolates of Rhizoctonia sp. were obtained from the diseased plants. Of the isolates, two were identified as Rhizoctonia solani AG-2-1 based on the morphological characteristics and anastomosis test, and three were as $R$. solani AG-4. Two isolates each of $R$. solani AG-2-1 and AG-4 were tested for pathogenicity on broccoli by artificial inoculation. All the tested isolates induced basal stem rot symptoms on the inoculated plants. The symptoms were similar to those observed in the fields investigated. This is the first report of basal stem rot of broccoli caused by AG-2-1 and AG-4 in Korea.

Keywords: Anastomosis Group; Basal Stem Rot; Broccoli; Pathogenicity; Rhizoctonia solani

\section{Introduction}

Broccoli (Brassica oleracea L. var. italica Plenck) is a popular vegetable grown worldwide. The vegetable is also widely grown in Korea. Basal stem rot symptoms were frequently observed on broccoli plants grown in farmers' fields located in Gimje and Jeju, Korea during disease surveys carried out in November and December 2019. The authors collected diseased plant samples from the broccoli fields and isolated fungi to determine the cause of the disease. Rhizoctonia sp. was most frequently isolated from the diseased plant samples. Rhizoctonia spp. are identified based on the morphological characteristics and anastomosis test [1,2]. Of the Rhizoctonia spp., Rhizoctonia solani Kühn has the most strains and hosts compared to other species. Many anastomosis groups are reported to exist in $R$. solani and known to have different genetic and pathological characteristics [2]. Anastmosis groups of $R$. solani isolates are identified by hyphal fusion reaction with tester isolates. In this study, identification of Rhizoctonia sp. isolates from diseased broccoli plants was carried out based on the morphological characteristics and anastomosis test. In addition, pathogenicity of the isolates was investigated by inoculation test.

\section{Materials and Methods}

\section{Field Survey and Collection of Samples}

Broccoli fields were surveyed at locations Gimje and Jeju in Korea in November and December 2019. Three sites were observed in the field, and 100 plants at each site were investigated for disease incidence. The diseased broccoli plants were collected to isolate causal fungus.

\section{Isolation}

Nine to $15 \mathrm{~mm}^{2}$ lesion pieces cut from the diseased plant parts were plated on $2 \%$ water agar (WA) after surface-sterilizing with $1 \%$ sodium hypochlorite solution for one minute. Fungi were isolated from the lesion pieces after one to two days of incubation at $25{ }^{\circ} \mathrm{C}$. The fungal isolates were transferred to potato dextrose agar (PDA) slants and used for identification and pathogenicity test.

\section{Investigation of Morphology and Anastomosis Test}

Rhizoctonia sp. isolates obtained from the diseased plants 
were cultured on PDA in $9 \mathrm{~cm}$-diameter petri dishes at $25{ }^{\circ} \mathrm{C}$ for 10 days and examined for the morphological characteristics. The Rhizoctonia sp. isolates were tested to classify anastomosis groups using tester isolates of $R$. solani as previously described [3]. The $R$. solani tester isolates AG-1 (KACC 40101), AG-2-1 (KACC 40119), AG-2-2 (40125), AG-3 (KACC 40138), AG-4 (KACC 40139), and AG-5 (KACC 40146) were obtained from the Agricultural Microbiology Division, National Institute of Agricultural Sciences in Korea.

\section{Pathogenicity Test}

Broccoli seeds were sown in circular plastic pots (height, $9 \mathrm{~cm}$; upper diameter, $10 \mathrm{~cm}$; lower diameter, $7 \mathrm{~cm}$ ) filled with soil in the greenhouse at $20-28{ }^{\circ} \mathrm{C}$. Twenty six-day-old plants of broccoli grown in the pots were used for inoculation tests. Selected isolates of Rhizoctonia sp. were tested for their pathogenicity on the broccoli plants. Mycelial disks of $6 \mathrm{~mm}$ in diameter were cut from the margins of actively growing cultures of each isolate on PDA and placed at the soil surface level of the broccoli plants. Inoculated plant pots were placed in plastic boxes $(60 \mathrm{~cm} \times 43 \mathrm{~cm} \times 33 \mathrm{~cm})$ with
$100 \%$ relative humidity at room temperature $\left(24-26^{\circ} \mathrm{C}\right)$ for two days. Then, the inoculated plant pots were removed from the boxes and kept indoors. The virulence of the isolates was rated based on the degree of basal stem rot symptoms five days after inoculation. The inoculation test was performed in three replicates.

\section{Results}

\section{Symptoms and Disease Incidence}

Basal stem rot symptoms were frequently observed on broccoli plants grown in the fields investigated. The symptoms began on the plant parts at the soil surface. The diseased plants wilted and blighted in the early stage of the plant growth (Figures $1 \mathrm{~A} \& 1 \mathrm{~B}$ ). The basal stem of the infected plant receded and was thin, discolored, and rotten (Figure 1C). The diseased plants were retarded in their growth and fell down in the medium stage of the plant growth (Figure 1D). The basal stems of the diseased plants turned dark brown and rotted (Figure 1E). The incidence of diseased plants in the fields investigated at two locations in Korea during the disease surveys was $1-10 \%$ (Table 1 ).

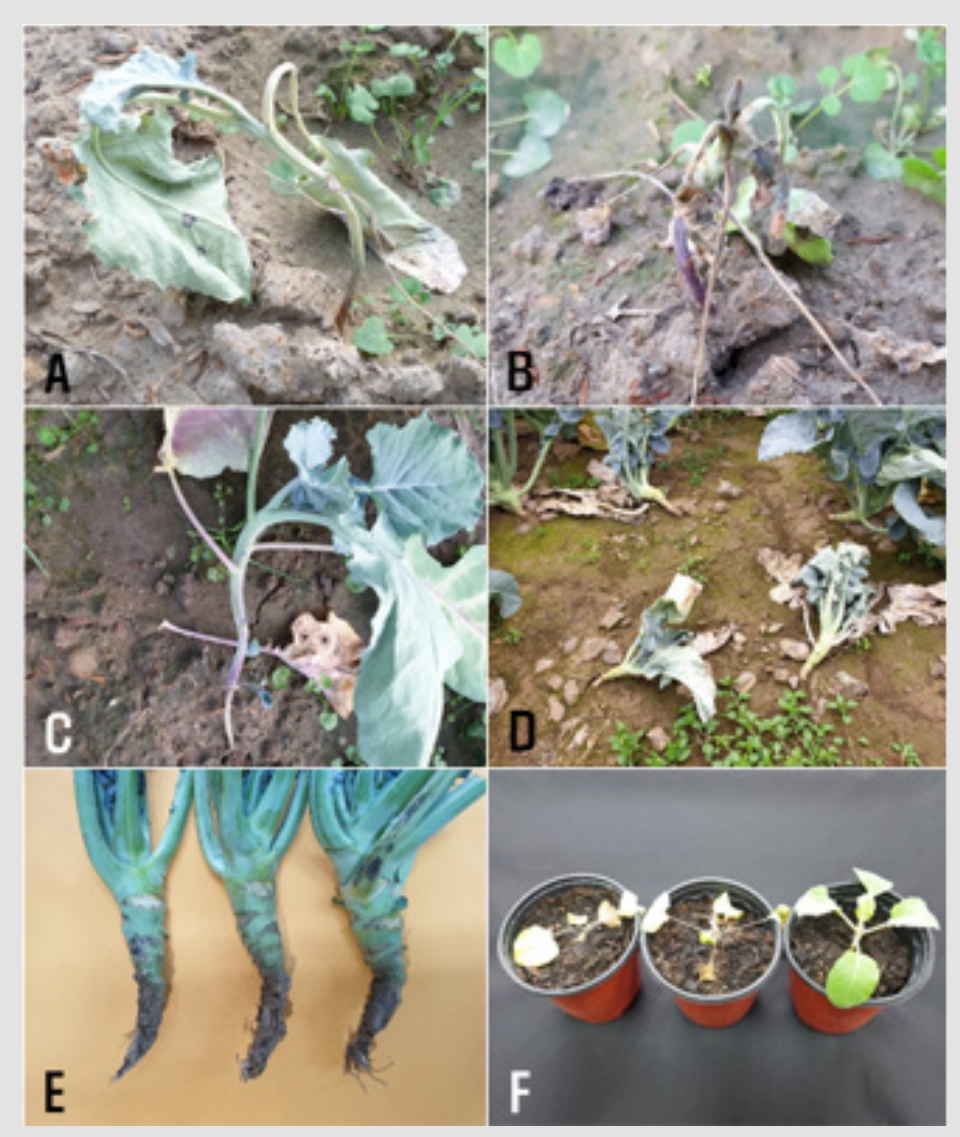

Figure 1: Basal stem rot symptoms of broccoli plants.

A-C: Symptoms in the early stage of the plant's growth observed in the field;

D and E: Symptoms in the medium stage of the plant's growth observed in the field;

F: Symptoms (left, AG-2-1 inoculated; center, AG-4 inoculated; right, non-inoculated) induced by artificial inoculation tests with $R$. solani isolates. 
Table 1: Incidence of basal stem rot on broccoli plants in the fields located in Gimje and Jeju in Korea in 2019.

\begin{tabular}{|c|c|c|c|c|}
\hline Location Investigated & Month Investigated & No. of Fields Investigated & No. of Fields with Disease & \% Diseased Plants* \\
\hline Gimje & November & 1 & 1 & $1-5$ \\
\hline Jeju & December & 2 & 2 & $1-10$ \\
\hline
\end{tabular}

*Three sites were observed in the field, and 100 plants at each site were investigated.

\section{Isolation and Identification}

Five isolates of Rhizoctonia sp. were obtained from basal stems of the diseased plants. All the isolates were identified as R. solani based on the morphological characteristics as per descriptions from previous studies [1,2]. Of five isolates of $R$. solani, two were classified as $R$. solani AG-2-1 by anastomosis test, and three as $R$. solani AG-4. Anastomosis reactions between the tested isolates and the tester isolates of $R$. solani AG-2-1 and AG-4 observed by light microscope are shown in Figures 2A \& 2B. The colony of $R$. solani AG-2-1 cultured on PDA showed brown concentric zones (Figure 2C). The colony of $R$. solani AG-4 cultured on PDA were whitish light brown, and sclerotia were not produced on the medium (Figure 2D).

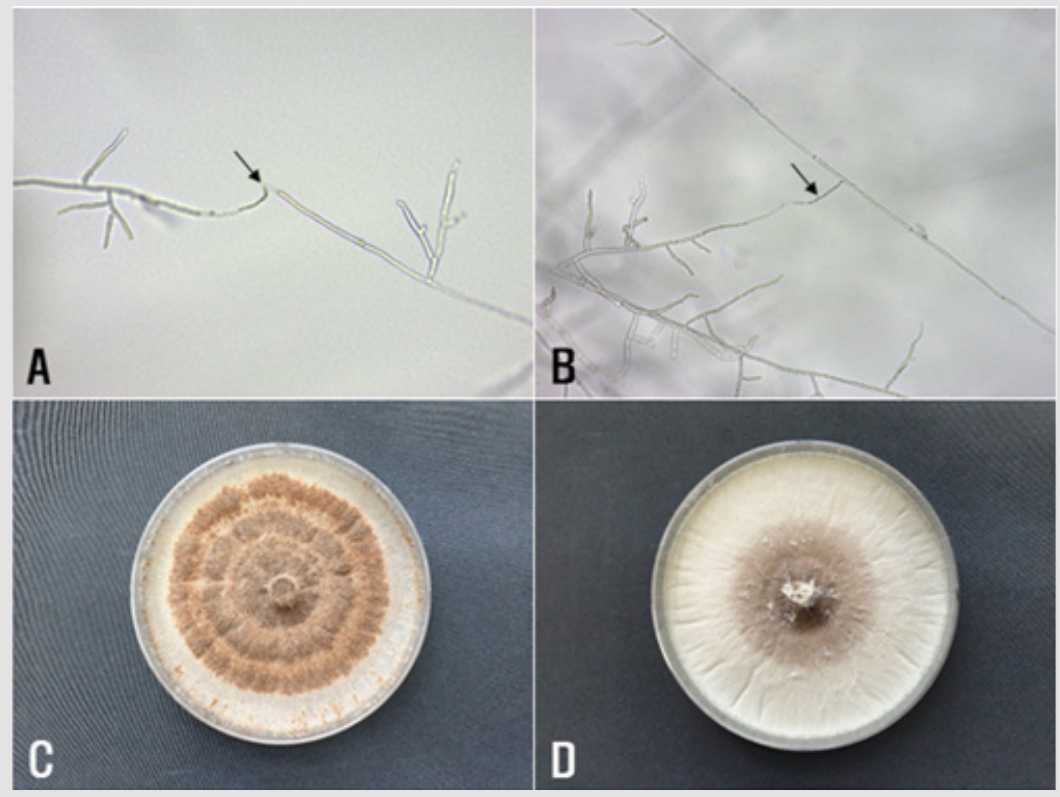

Figure 2: Anastomosis test of Rhizoctonia solani isolates from broccoli and cultural appearance of the isolates.

A and B: Anastomosis reactions between the tested isolates (left) and the tester isolates (right) of R. solani AG-2-1 and AG-4 observed by light microscope, respectively. The arrows indicate points of hyphal anastomosis;

C and D: Colonies of R. solani AG-2-1 and AG-4 isolates grown on PDA at $25^{\circ} \mathrm{C}$ for 10 days, respectively.

\section{Pathogenicity}

Two isolates each of $R$. solani AG-2-1 and AG-4 were tested for pathogenicity on broccoli by artificial inoculation. All the tested isolates of the two anastomosis groups induced basal stem rot on

Table 2: Pathogenicity of Rhizoctonia solani AG-2-1 and AG-4 isolates on broccoli plants by artificial inoculation.

\begin{tabular}{|c|c|c|}
\hline \multirow{2}{*}{ Anastomosis Group } & Isolate No. & Location Source of Isolates \\
\hline \multirow{2}{*}{ AG-2-1 } & RS1933 & Gimje \\
\cline { 2 - 4 } & RS1934 Gimje & Jeju \\
\hline \multirow{2}{*}{ AG-4 } & RS1930 & Jeju \\
\cline { 2 - 4 } & RS1931 & \\
\hline Control & & \\
\hline
\end{tabular}

*Disease severity was rated five days after inoculation. + : severe basal stem rot induced, - : no symptom. the inoculated plants, whereas no symptom was observed on the control plants (Table $2 \&$ Figure 1F). The symptoms induced by the artificial inoculation of the plants were similar to those observed in plants from the fields investigated. The isolates which induced symptoms on the plants were re-isolated from the lesions. 


\section{Discussion}

$R$. solani is reported to cause various diseases such as dampingoff, seedling rot, stem and root rot, wire stem, basal stem rot, etc. in many crops [4-6]. It has been reported that $R$. solani AG-2-1 and AG-2-2 VI cause damping-off and foot rot of broccoli in Japan, respectively $[7,8]$. However, there has been no report of basal stem rot on broccoli caused by $R$. solani AG-2-1 and AG-4. This is the first report of basal stem rot of broccoli caused by AG-2-1 and AG-4 in Korea.

Anastmosis groups AG-1 through 13 of $R$. solani have been reported, and some anastomosis groups of $R$. solani are further divided into subgroups by cultural type, pathogenicity, DNA-DNA hybridization, rDNA-ITS sequence analysis, etc. [9]. It is reported that $R$. solani AG-4 is divided into subgroups HG- I, HG- II, and HG-II by rDNA-ITS sequence analysis [10] and analysis of fatty acids [11]. The authors identified $R$. solani AG-4 causing basal stem rot of broccoli based on the morphological characteristics and anastomosis test. It is considered that subgroups of $R$. solani AG-4 isolates identified in this study could be classified by the aforementioned methods via further study.

\section{Acknowledgement}

This study was supported by a research grant(PJ014507012020) from the Rural Development Administration, Korea.

\section{References}

1. Parmeter JR, Whitney HS (1970) Taxonomy and nomenclature of the imperfect state. In: Parmeter JR (Ed.) Rhizoctonia solani, Biology and Pathology. University of California Press, Los Angeles and London, UK, pp. 7-19.

\section{ISSN: 2574-1241}

DOI: $10.26717 /$ BJSTR.2020.32.005294

Wan-Gyu Kim. Biomed J Sci \& Tech Res

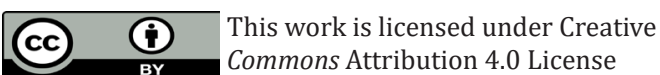

Submission Link: https://biomedres.us/submit-manuscript.php
2. Sneh B, Burpee, L, Ogoshi A (1991) Identification of Rhizoctonia Species. In: Sneh B, Burpee L (Eds.) APS Press, The American Phytopathological Society, St. Paul, Minnesota, USA, pp. 133.

3. Kim WG, Cho WD, Lee YH (1994) Anastomosis groups and cultural characteristics of Rhizoctonia solani isolates from crops in Korea. Kor J Mycol 22(4): 309-324.

4. Kim WG (1996) Pathogenicity of anastomosis groups and cultural types of Rhizoctonia solani isolates on crops. Korean J Plant Pathol 12(1): 2132.

5. Kim WG, Cho WD, Ryu HY (1995) Diagnosis and Control of Rhizoctonia Diseases on Crops (in Korean). National Agricultural Science and Technology Institute, Suwon, Korea, pp. 167.

6. Farr DF, Rossman AY (2020) Fungal Databases, U.S. National Fungus Collections, ARS, USDA.

7. Misawa T, Yamazaki K, Takada K (2013) Damping-off of broccoli caused by Rhizoctonia solani AG-2-1. Ann Rept Plant Prot North Japan 64: 60-64.

8. Misawa T, Kubota M, Sasaki J, Kuninaga S (2015) First report of broccoli foot rot caused by Rhizoctonia solani AG-2-2 IV and pathogenicity comparison of the pathogen with related pathogens. J Gen Plant Pathol 81(1): 15-23.

9. Kuninaga $S$ (2002) Current situation of the taxonomy of the genus Rhizoctonia and the R. solani species complex. Jpn J Phytopathol 68(1): 3-20.

10. Kuninaga S, Yokosawa R (1984) DNA base sequence homology in Rhizoctonia solani Kühn. IV. Genetic relatedness within AG-4. Ann Phytopathol Soc Jpn 50(3): 322-330.

11. Stevens JJ, Jones RK (2001) Differentiation of the homogeneous groups of Rhizoctonia solani anastomosis group 4 by analysis of fatty acids. Phytopathology 91(9): 821-830.

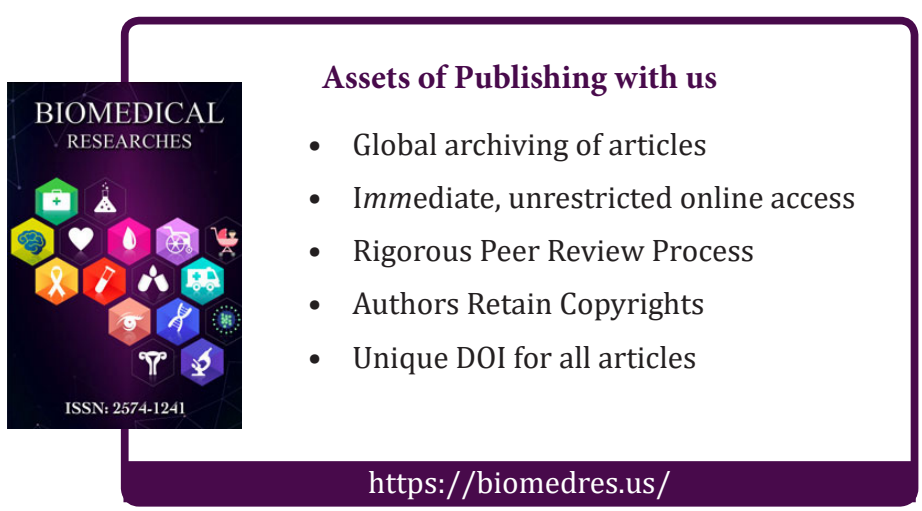

